\title{
Caste and wing loading in a social wasp (Hymenoptera, Vespidae, Dolichovespula maculata)
}

\author{
Christopher K. Starr', Robert S. Jacobson², Joan W. Krispyn³, Joshua A. Spiers' \\ I University of the West Indies, St Augustine, Trinidad \& Tobago 2 Greer Laboratories, Lenoir, NC 28645, \\ USA 3 Gracewood State School \& Hospital, Gracewood, GA 30815, USA \\ Corresponding author: Christopher K. Starr (ckstarr@gmail.com)
}

Academic editor: Maksim Proshchalykin | Received 17 May 2021 | Accepted 21 July 2021 | Published 24 August 2021

http://zoobank.org/7DDC17C0-CD1D-4270-88D7-EC9491585C94

Citation: Starr CK, Jacobson RS, Krispyn JW, Spiers JA (2021) Caste and wing loading in a social wasp (Hymenoptera, Vespidae, Dolichovespula maculata). In: Proshchalykin MYu, Gokhman VE (Eds) Hymenoptera studies through space and time: A collection of papers dedicated to the $75^{\text {th }}$ anniversary of Arkady S. Lelej. Journal of Hymenoptera Research 84: 381-390. https://doi.org/10.3897/jhr.84.68800

\begin{abstract}
Variation in wing design and wing loading according to body weight is well studied across taxa of birds and flying insects. Comparable studies have not been made in the few insects that show substantial size variation within the same phenon of a single species. We examine body measures of adults of the social wasp Dolichovespula maculata (Linnaeus, 1763), with particular attention to the limbs and wing loading. As expected, measures of the length of the legs scales isometrically with overall body weight and size. Against expectation, wing size also scales isometrically with body weight and size. This does not match the general pattern of comparison across species of flying animals, in which larger individuals have relatively larger wings, as a partial compensation for greater wing loading. We suggest that wing size in $D$. maculata may be constrained by the demands of life in a crowded nest.
\end{abstract}

\section{Keywords}

allometry, flight, polymorphism

\section{Introduction}

Ever since Thompson's (1917) classic study, it has been understood that body form varies with overall body size in meaningful ways. Furthermore, body form in flying animals is believed to be tightly constrained by the heavy mechanical and energetic

Copyright Christopher K. Starr et al. This is an open access article distributed under the terms of the Creative Commons Attribution License (CC BY 4.0), which permits unrestricted use, distribution, and reproduction in any medium, provided the original author and source are credited. 
demands of flight (Alexander 2002). A key parameter in studies of scaling and design of flying animals is wing loading, the ratio of body weight to wing surface area. In a broad comparative study of 143 species of birds with body weights ranging from $2.6 \mathrm{~g}$ to $11.6 \mathrm{~kg}$, Poole (1938) showed that in larger species the wings are somewhat larger relative to linear body size, but somewhat smaller relative to body weight, so that wing loading increases with body size. This pattern as since been widely corroborated in birds (e.g. Pennycuick 1972, 1987; Dorst 1974; Warham 1977; Alexander 2002). The scaling relationship, then, is a compromise between geometric similarity and constant wing loading. The several interspecific studies of bees and other insects give results consistent with this pattern (Byrne 1988; Danforth 1989; Dyer 1991; Bullock 1999; Dudley 2000; Davreau et al. 2005). As another well established rule in birds, larger species tend to have higher aspect ratio, the ratio of wing length to width, so that their wings are relatively narrower (Warham 1977; Pennycuick 1987, 2008; Alexander 2002). One might reasonably expect to find within the same relationships within a given species, i.e. a) a compromise between constant body size and constant wing loading, and b) greater aspect ratio in larger individuals. However, this question is not as readily tractable within as between species. While some taxa of flying animals show interspecific size variation across an order of magnitude or more, same-sex adults are close to uniform within most species that fly well. Many social wasps and bees show substantial variation among nestmate females, but in most of these the queens and workers are of two distinct phena. Among the very few groups in which females show substantial, continuous size variation with only a statistical difference between castes are pocket-making bumble bees (Apidae: Bombus spp.) (Plowright and Laverty 1984; Goulson 2010) and some vespine wasps (Vespidae) (Edwards 1980; Greene 1991; Yamane and Yamane 2021). Dolichovespula maculata (Linnaeus, 1763) is among the species that fit this pattern well (Greene 1991). This robust social wasp (Fig. 1) is found over the greater part of North America north of Mexico, in much of which it is common (Akre et al. 1980; Kimsey and Carpenter 2012). It builds a nest of several horizontal combs surrounded by an envelope of several layers of rough carton (Fig. 2), typically on a tree, bush or side of a building. Several aspects of this species have been investigated (Greene 1991; Archer 2006). Felippotti et al. (2009) noted that the size of new nest cells tends to increase during the colony cycle, with different sizes among cells of the same age. This is consistent with a more or less continuous size distribution among same-sex nestmates. Our working prediction, then, is that the compromise between geometrical similarity and uniform wing loading known from studies across species will be mirrored in the pattern within this single species. At the same time, there is no reason to expect a similar relationship in the other limbs, the legs. We predicted that leg length will increase isometrically with a linear measure of body size in $D$. maculata.

\section{Materials and methods}

Our material was drawn from three colonies of Dolichovespula maculata collected in 2005 and 2006 in Avery, Caldwell and Watauga Counties, North Carolina, USA. The 


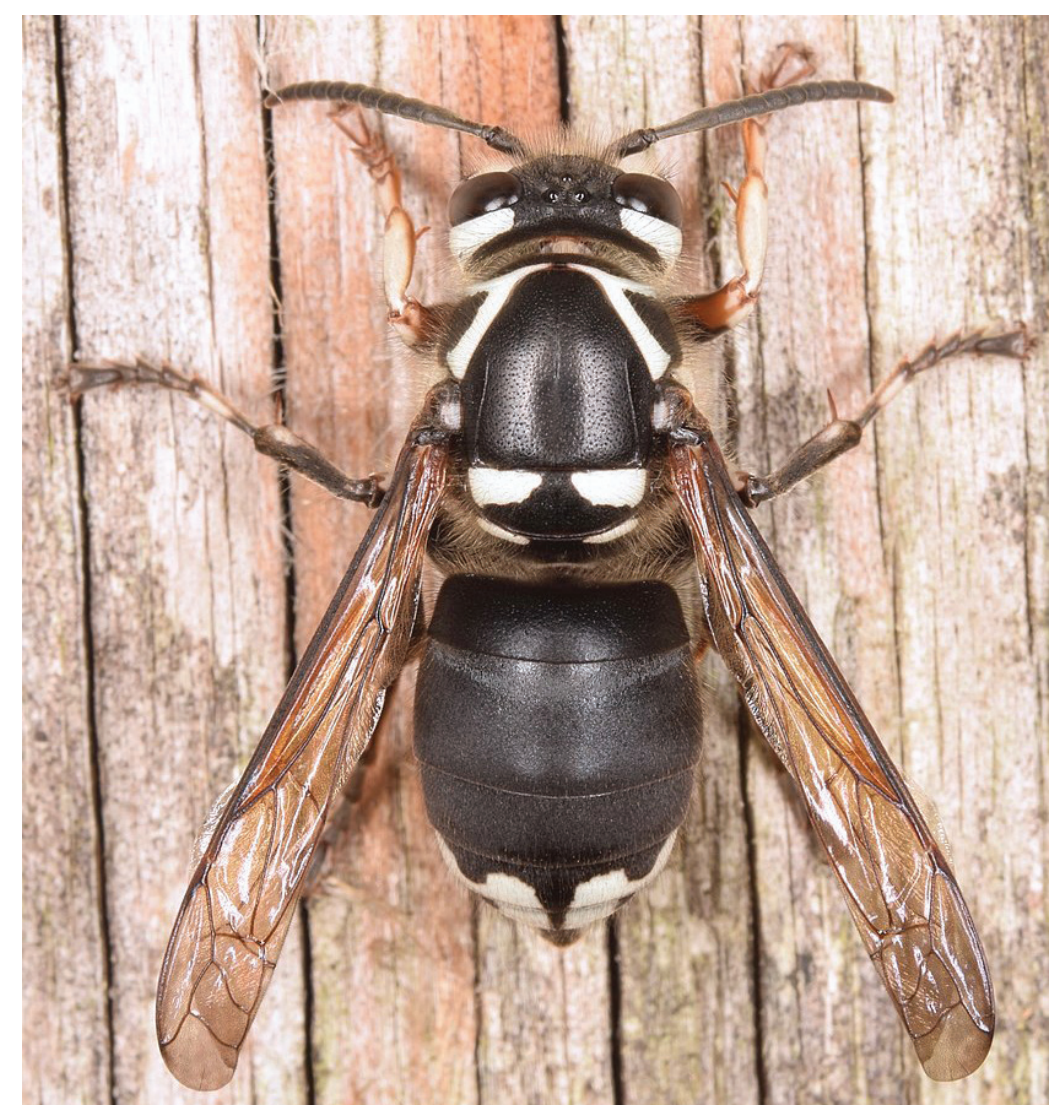

Figure I. Dolichovespula maculata adult female. Source: Wikimedia Commons.

colonies were killed and preserved by freezing in airtight plastic bags very soon after collection. The wasps were removed briefly for dissection of their venom glands for a pharmacological study and then re-frozen until utilized for the present project in July 2007. We thawed them in a refrigerator for several hours and then chose samples of 147 females and 54 males representative of the size range in the available material. We weighed these (wet weight) to the nearest microgram, then air-dried them at $60{ }^{\circ} \mathrm{C}$ for at least 12 hours and weighed them again (dry weight). Earlier studies show a strong positive correlation between the two weight measures in insects (e.g. Darforth 1989). As an additional convenient index of overall body size, we measured the length of the mesoscutum along its midline to the nearest $0.04 \mathrm{~mm}$ with an ocular micrometer in a dissecting microscope. This is analogous to Cane's (1987) use of the width of the mesoscutum as a relative measure of overall size. We took photomicrographs of the forewing and hind leg against a one-millimeter grid, then used these micrographs to record forewing length, forewing width and hind-tibia length (Fig. 3) to the nearest $0.01 \mathrm{~mm}$, indifferently using the left or right limb. In those few cases where the ends of both forewings were frayed, we measured the length of the first discal cell and extrapolated this to estimate forewing length. There was no discernible difference among 


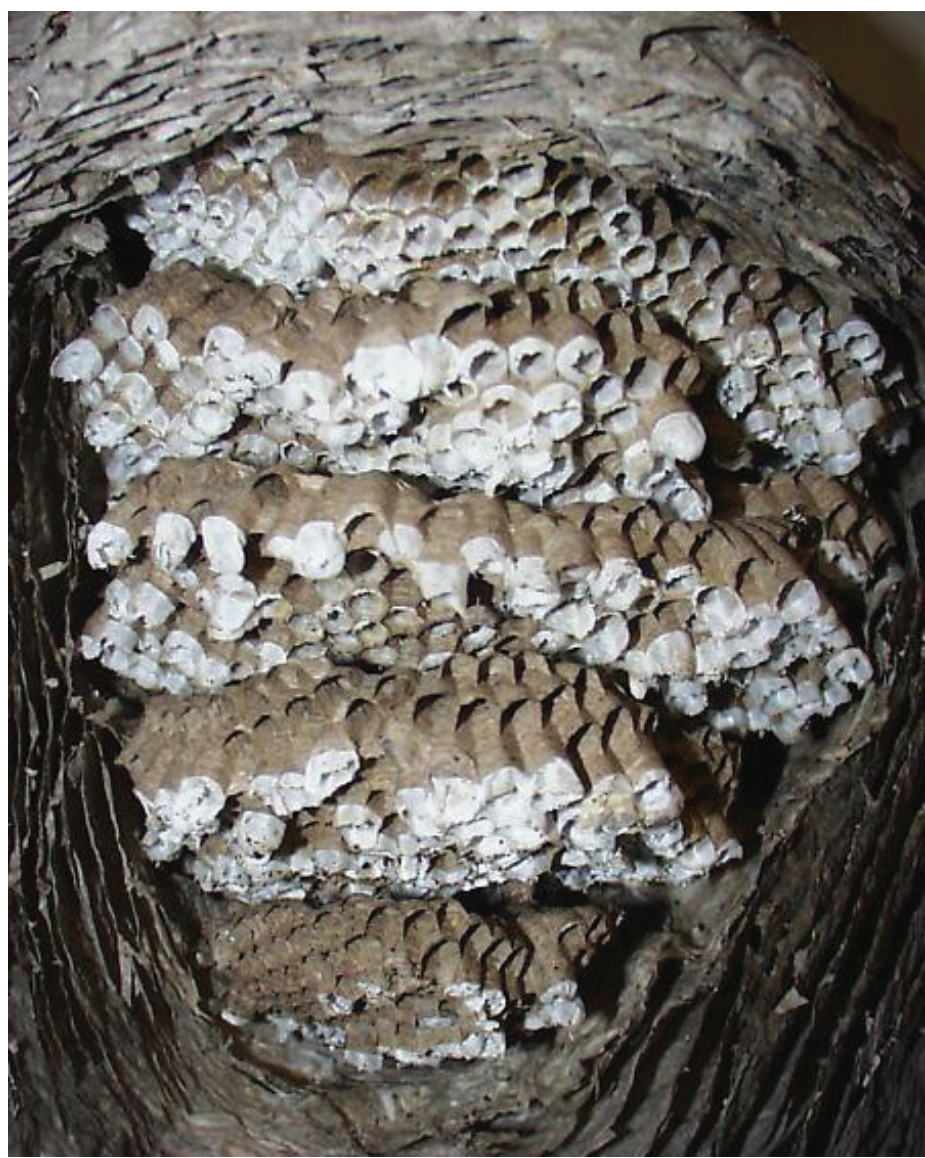

Figure 2. Cross-section of a mature nest of Dolichovespula maculata. Source: BugGuide.net.

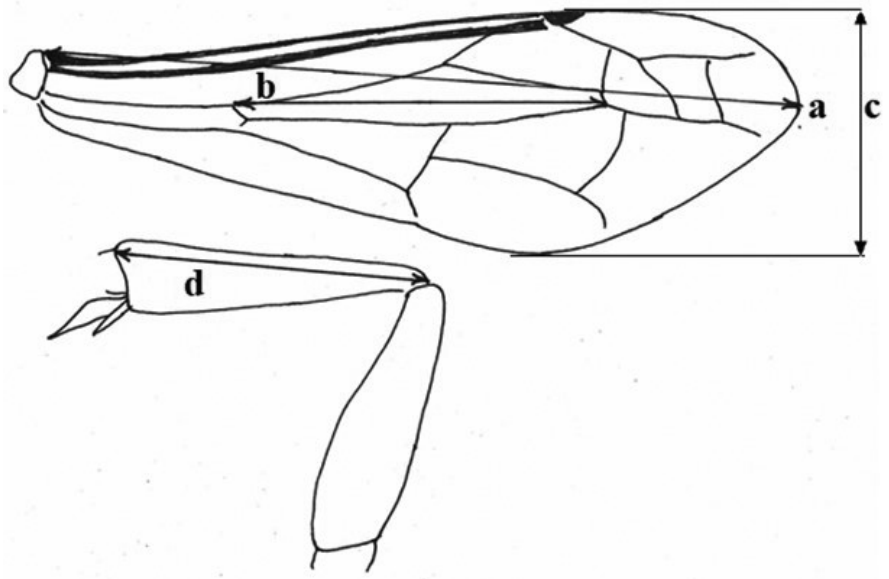

Figure 3. Linear measures of limbs in Dolichovespula maculata a forewing length from base of the costal vein to tip of the wing $\mathbf{b}$ length of first discal cell $\mathbf{c}$ maximum forewing width $\mathbf{d}$ length of fore-tibia. 
specimens in the relative sizes of the forewing and hindwing. Similarly, preliminary measurements showed no significant variation in aspect ratio of the forewing among individuls. In all females the width/length ratio of the forewing was between 0.276 and 0.313 , with clustering around 0.29 ; the males showed a very similar pattern. Accordingly, we accept forewing length as the sole index of linear wing size within this one species. Similarly, there was no discernible variation in the relative lengths of the three legs or their component parts, so that the length of the hind-tibia serves as a convenient index of overall leg length. A preliminary examination showed no evident difference between the sexes in the pattern of size variation. However, the size ratio of the largest over the smallest females in our sample was 8.00 (dry weight) or 1.46 (linear measure), while the corresponding figures for males were 5.68 and 1.34. As a result, we restrict our analysis to females, with the working assumption that our results apply equally well to males.

\section{Results}

As expected, given our attempt to draw the 147 females from the full size range of the available material, their wet weights, dry weights, mesoscutum lengths, forewing lengths and hind-tibia lengths were not normally distributed (Shapiro-Wilk test, $\mathrm{p}<$ 0.01). All compared pairs of parameters showed a strong positive correlation across specimens of different sizes (Spearman's ranked correlation, $r_{\text {s }}$ between 0.87 and 0.97 , $p<0.01)$. The trendline of dry weight (y) as a function of wet weight $(\mathrm{y})$ departed slightly from linear: $y=0.44 x^{1} \cdot{ }^{09}$. Accordingly, dry weight is the preferred index of

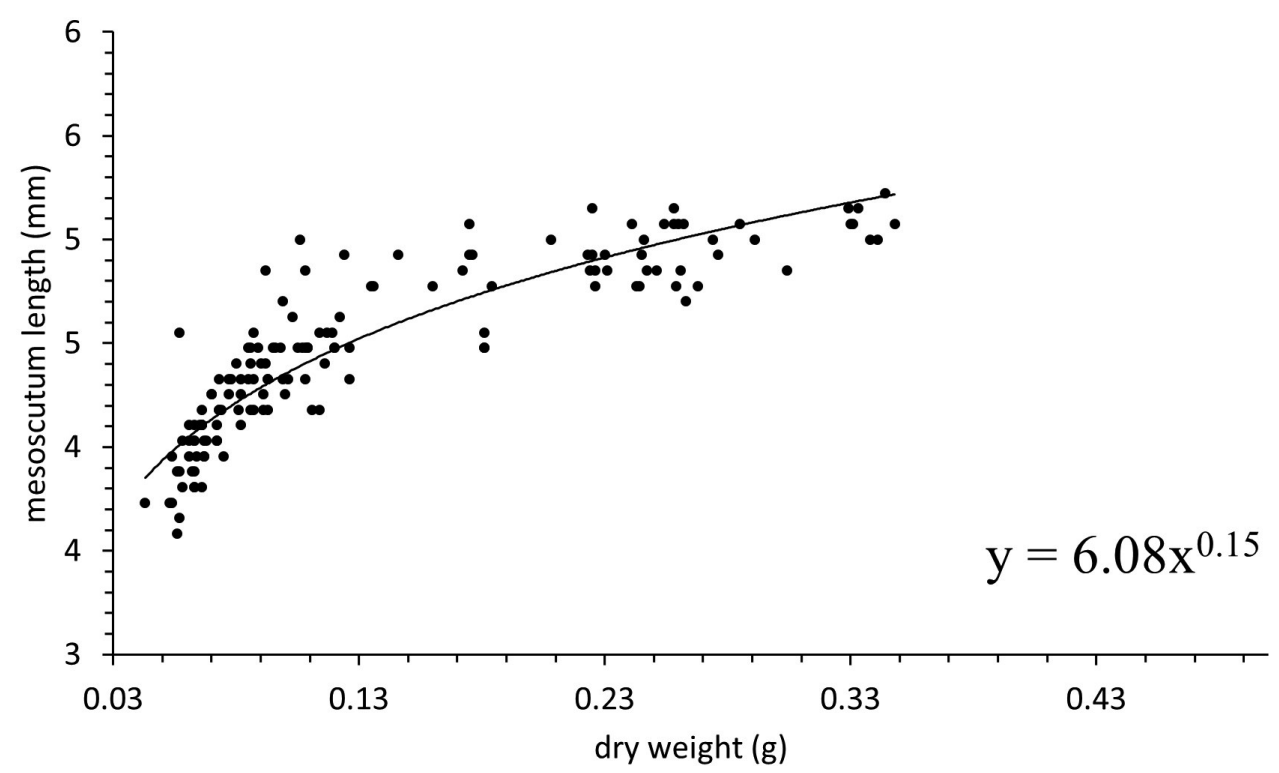

Figure 4. Mesoscutum length as a function of dry weight in Dolichovespula maculata females. 

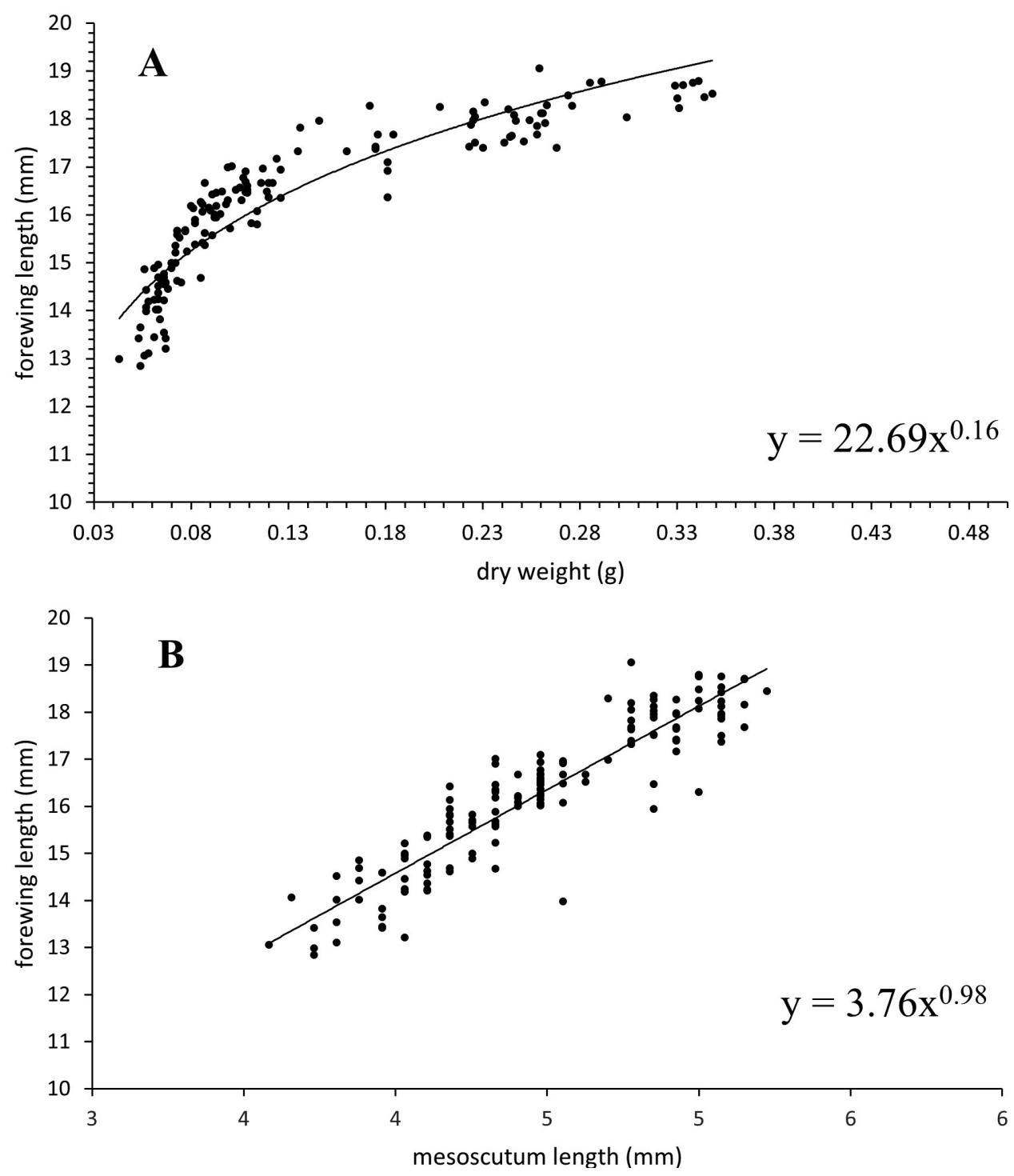

Figure 5. Forewing length as a function of $\mathbf{A}$ dry weight and $\mathbf{B}$ mesoscutum length in Dolichovespula maculata females.

overall body weight, as smaller individuals may have lost more water than large individuals during the months frozen despite the sealed containers. Fig. 4 shows the relationship between mesoscutum length and dry weight, the two measures of overall body size used here. Linear wing size as manifested by the length of the forewing is isometric with a linear measure of dry weight (Fig. 5). Likewise, hind-tibia length as a measure of leg length is isometric with a linear measure of dry weight (Fig. 6). With forewing length as a linear measure of relative wing area, our results indicate a marked increase in wing loading with increased body size (Fig. 7). 

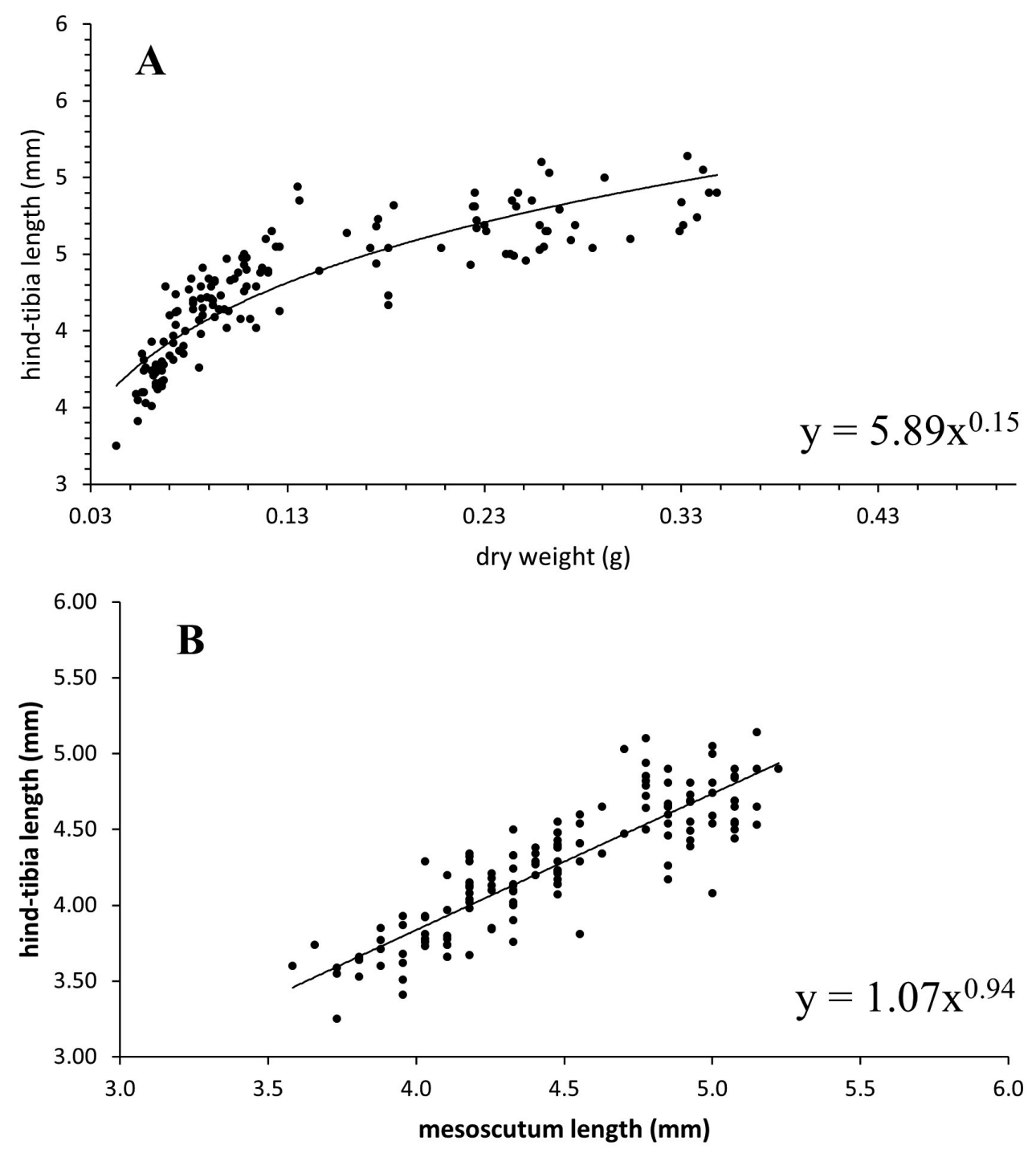

Figure 6. Hind-tibia length as a function of $\mathbf{A}$ dry weight and $\mathbf{B}$ mesoscutum length in Dolichovespula maculata females.

\section{Discussion}

It is convenient that whole-body dry weight is a fairly constant fraction of wet weight across all sizes. This corroborates the use of dry weight as a practical measure of overall body size in studies of land arthropods. As expected, wing loading is appreciably greater in larger individuals of both sexes. However, the isometry of wing size as a function of with body weight was not expected and goes against the predicted compromise between geometric constant relative wing area and constant wing loading, as noted in cross-species studies of taxa of flying animals. Why do larger individuals of 


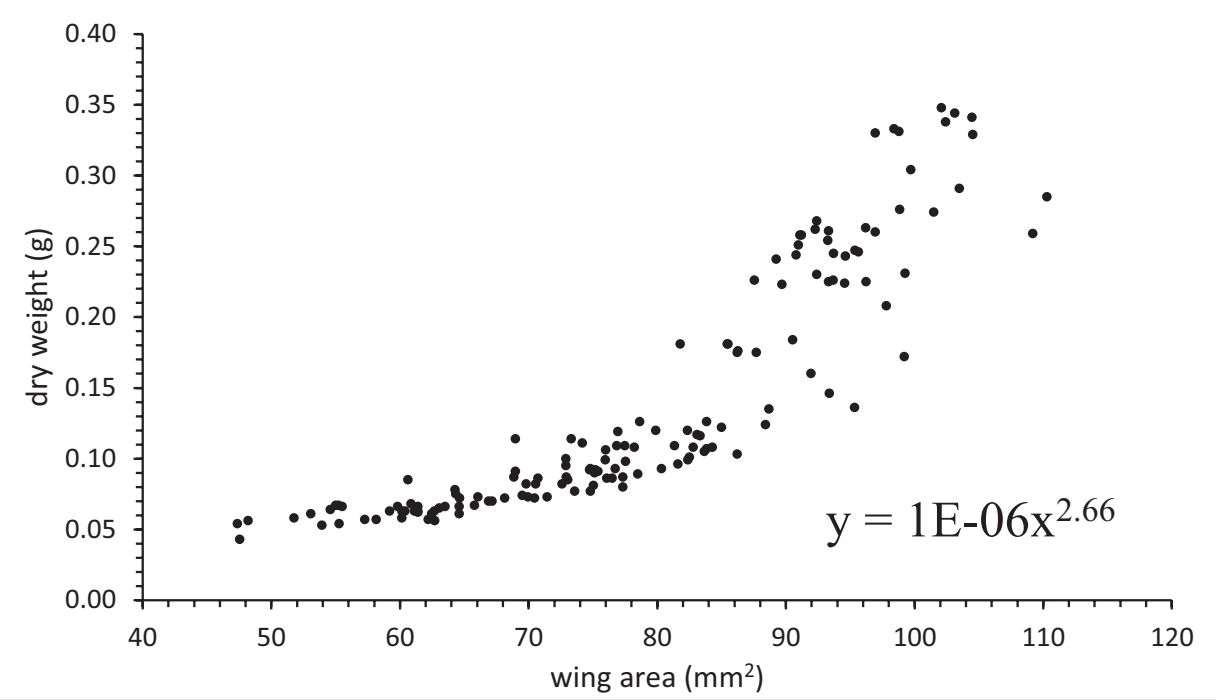

Figure 7. Wing loading according to body size in Dolichovespula maculata females.

Dolichovespula maculata, as actively flying insects, not have relatively larger wings as a partial compensation for greater wing loading? The conspicuous allometric differences in body proportions among nestmates in many ants (e.g. Hölldobler and Wilson 2011) would seem to speak against developmental constraints. On the other hand, Dolichovespula maculata's overall lack of allometry across a substantial range of body sizes could be seen as an indication of such developmental constraints. As a working conjecture, we suggest that the crowded inner environment of the nest may impose a high cost on limbs that project unduly from the body.

\section{Conclusions}

Despite considerable size variation among same-sex individuals, Dolichovespula maculata adults are isometric in all studied pairs of linear body measures. In particular, the wings are not relatively larger in larger individuals, which therefore show substantially greater wing loading. We hypothesize that wing size is constrained by the need to live and move inside a highly restricted nest space.

\section{Acknowledgements}

This paper is dedicated to veteran hymenopterist Arkady S. Lelej on the occasion of his $75^{\text {th }}$ birthday. Thanks to Adrian Hailey for statistical comment and to the journal's reviewers for useful criticism. The authors have no support to report. 


\section{References}

Akre RD, Greene A, Macdonald JF, Landolt PJ, Davis HG (1980) Yellowjackets of America north of Mexico. U.S. Department of Agriculture, Agriculture Handbook 552: 1-102. https:// naldc.nal.usda.gov/download/CAT82762500/PDF

Alexander DE (2002) Nature's Flyers. Johns Hopkins University Press, Baltimore, 358 pp.

Archer ME (2006) Taxonomy, distribution and nesting biology of species of the genus Dolichovespula (Hymenoptera, Vespidae). Entomological Science 9(3): 281-293. https://doi. org/10.1111/j.1479-8298.2006.00174.x

Bullock SH (1999) Relationships among body size, wing size and mass in bees from a tropical dry forest in Mexico. Journal of the Kansas Entomological Society 72: 426-439. https://www. jstor.org/stable/25085929

Byrne DN (1988) Relationship between wing loading, wingbeat frequency and body mass in homopterous insects. Journal of Experimental Biology 135: 9-23. https://doi.org/10.1242/ jeb.135.1.9

Cane JH (1987) Estimation of bee size using intertegular span. Journal of the Kansas Entomological Society 60: 145-147. https://www.jstor.org/stable/25084877

Danforth BN (1989) The evolution of hymenopteran wings: the implications of size. Journal of Zoology 218: 247-276. https://doi.org/10.1111/j.1469-7998.1989.tb02536.x

Darveau C-A, Hochachka PW, Welch KC, Roubik DW, Suarez RK (2005) Allometric scaling of light energetics in Panamanian orchid bees: A comparative phylogenetic approach. Journal of Experimental Biology 208: 3581-3591. https://doi.org/10.1242/jeb.01776

Dorst J (1974) The Life of Birds (Vol. 1). Columbia University Press, New York 349 pp.

Dudley R (2000) The biomechanics of insect flight. Princeton University Press, Princeton, 476 pp. https://doi.org/10.1515/9780691186344

Dyer FC (1991) Coadaptation of colony design and worker performance in honeybees. In: Smith DR (Ed.) Diversity in the Genus Apis. Westview, Boulder, 213-245. https://doi. org/10.1201/9780429045868-11

Edwards R (1980) Social Wasps. Rentokil, East Grinstead, 398 pp.

Felippotti GT, Tanaka GM, Noll FB, Wenzel JW (2009) Discrete dimorphism among castes of the bald-faced hornet Dolichovespula maculata (Hymenoptera: Vespidae) in different phases of the colony cycle. Journal of Natural History 43: 2481-2490. https://doi. org/10.1080/00222930903154763

Goulson D (2010) Bumble Bees; their Behaviour, Ecology and Conservation. Oxford University Press, Oxford, 317 pp.

Greene A (1991) Dolichovespula and Vespula. In: Ross KG, Matthews RW (Eds) The Social Biology of Wasps. Cornell University Press, Ithaca, 263-305. https://doi.org/10.7591/9781501718670-011 Hölldobler B, Wilson EO (2011) The Leafcutter Ants. W.W. Norton, New York, 160 pp.

Kimsey LS, Carpenter JM (2012) The Vespinae of North America (Vespidae, Hymenoptera). Journal of Hymenoptera Research 28: 37-65. https://doi.org/10.3897/jhr.28.3514

Pennycuick CJ (1972) Animal Flight. Edward Arnold, London, 64 pp.

Pennycuick CJ (1987) Flight of seabirds. In: Croxall JP (Ed.) Seabirds: Feeding Biology and

Role in Marine Ecosystems. Cambridge University Press, Cambridge, 43-62.

Pennycuick CJ (2008) Modelling the Flying Bird. Academic, Amsterdam, 480 pp. 
Plowright RC, Laverty TM (1984) The ecology and sociobiology of bumblebees. Annual Review of Entomology 29: 175-199. https://doi.org/10.1146/annurev.en.29.010184.001135

Poole EI (1938) Weights and wing areas in North American birds. The Auk 55: 511-517. https://doi.org/10.2307/4078421

Thompson DW (1917) On Growth and Form. Cambridge University Press, Cambridge, 793 pp. Warham J (1977) Wing loading, wing shapes, and flight capabilities of Procellariiformes. New Zealand Journal of Zoology 4: 73-83. https://doi.org/10.1080/03014223.1977.9517938

Yamane Sk, Yamane Sô (2021) Vespinae. In: Starr CK (Ed.) Encyclopedia of Social Insects. Springer, Cham, Switzerland, 1000-1008. https://doi.org/10.1007/978-3-030-28102-1_133 